\title{
Development and validation of an Onchocerca ochengi microfilarial hamster model for onchocerciasis drug screens
}

\author{
Glory Enjong Mbah, Rene Bilingwe Ayiseh and Fidelis Cho-Ngwa*
}

\begin{abstract}
Background: Onchocerciasis, caused by the parasitic nematode, Onchocerca volvulus afflicts some 37 million people worldwide, and is the second leading infectious cause of blindness globally. The only currently recommended drug for treatment of the disease, ivermectin, is only microfilaricidal and has serious adverse effects in individuals co-infected with high loads of Loa loa microfilariae ( $\mathrm{mf})$, prompting the search for new and better drugs. Onchocerciasis drug discovery studies have so far been based on in vivo models using Onchocerca species which are not the closest to $O$. volvulus, and which may therefore, not adequately mimic the natural infection in humans. Therefore, this study was carried out to develop a better drug screening model for onchocerciasis, based on the use of cow-derived O. ochengi, the closest known relative of $O$. volvulus.
\end{abstract}

Methods: Mf of O. ochengi were injected subcutaneously at the nape of Syrian hamsters (Mesocricetus auratus) and BALB/C mice. The skin, and especially the earlobes of the animals were examined for $\mathrm{mf} 15-31$ days after infection. For selected model validation, the hamsters were treated with ivermectin at $150 \mathrm{or} 600 \mu \mathrm{g} / \mathrm{kg}$ body weight and examined 30 days after infection for $\mathrm{mf}$. For L. loa studies in hamsters, isolated $\mathrm{mf}$ were injected intraperitoneally and animal organs were examined on day 26 for $\mathrm{mf}$.

Results: The Syrian hamsters were found to be the more permissive to 0 . ochengi $\mathrm{mf}$ as fully viable $\mathrm{mf}$ were recovered from them on day 30 , compared to BALB/c mice where such mf were recovered on day 15 , but not 30. However, both animals were not permissive to L. loa $\mathrm{mf}$ even by day 15 . Interestingly, more than $50 \%$ of the total $O$. ochengi $\mathrm{mf}$ recovered were from the earlobes. The number of $\mathrm{mf}$ injected was directly proportional to the number recovered. Ivermectin at both concentrations tested completely eliminated the 0 . ochengi $\mathrm{mf}$ from the hamsters.

Conclusion: This study reveals the Syrian hamster as an appropriate small animal model for screening of novel compounds against $O$. ochengi, the closest known relative of $O$. volvulus.

Keywords: Onchocerciasis, Hamsters, Onchocerca ochengi, Drug screens, Loa loa, Microfilariae, Ivermectin

\section{Background}

Onchocerciasis is a neglected tropical disease caused by the filarial nematode, Onchocerca volvulus. It afflicts some 37 million people globally, with $99 \%$ of all the cases living in sub-Saharan Africa [1]. Onchocerciasis was estimated to account for 18.3 million disabilityadjusted life years (DALYs) in sub-Saharan Africa within 20 years [2]. It is the second leading infectious cause of

\footnotetext{
* Correspondence: fidelis.cho@ubuea.cm

Department of Biochemistry and Molecular Biology, Faculty of Science, University of Buea, Buea, South West Region, Cameroon
}

blindness worldwide [3]. The debilitating symptoms of onchocerciasis are attributed to inflammatory reactions to dead or dying $O$. volvulus microfilariae $(\mathrm{mf})$ in the skin and eyes $[4,5]$. The $\mathrm{mf}$ of $O$. volvulus is the stage of the parasite ingested during a blood meal on humans by the black fly (of genus, Simulium), in which the $\mathrm{mf}$ develop to the infective third stage larvae (L3), which may be transmitted to another person when bitten by the infected fly. Ivermectin, a microfilaricide is the only recommended drug used in many onchocerciasis elimination programs to break the transmission cycle by killing 
the $O$. volvulus mf. This drug is unfortunately, only a microfilaricide, and a major challenge with ivermectin treatment is the fact that it also kills L. loa $\mathrm{mf}$ in blood, a situation that often leads to severe adverse events (encephalopathy and death) in individuals with high $L$. loa $\mathrm{mf}$ load [6]. In addition, there is evidence of resistance or low response rate of $\mathrm{mf}$ to ivermectin $[7,8]$, emphasizing the need for new therapeutic options.

Efficacious small animal models in onchocerciasis for in vivo screens and preclinical studies, capable of closely mimicking the natural infection in humans are an urgent, unmet need. Immunocompetent rodents are nonpermissive to natural infections of $O$. volvulus [9], but experimentally injected $O$. lienalis $\mathrm{mf}$ have been shown to survive in mice, especially in inbred CBA mice [10, 11]. The severe-combined immunodeficient (SCID) mice have been exploited as a model for onchocerciasis and are permissive to $\mathrm{mf}$ of $O$. lienalis [12]. The O. lienalis $\mathrm{mf}$ mouse model has been validated with ivermectin and other filaricides $[10,13]$. However, $O$. ochengi in cattle is the closest in phylogeny to O. volvulus [14] and many onchocerciasis drug tests in vitro [15-18] and in naturally infected cows [19-21] have been done based on $O$. ochengi. However, the cow is too big, requires huge quantities of drugs, thereby rendering it too expensive for routine screening. Consequently, most funding bodies are reticent in considering the cow as a useful model for onchocerciasis. Both O. ochengi and O. volvulus are transmitted by the same black fly vectors of genus, Simulium. O. ochengi is confined to Africa and combines many important features of the human infection with $O$. volvulus [21]. O. ochengi also forms nodules with close resemblance to those of $O$. volvulus [22], which can be enumerated by palpation in situ or removed for analysis during immunological or chemotherapeutic studies. Moreover, both parasites are equally susceptible to the filaricides, ivermectin and suramin [23], and tetracyclines [24]. Molecular and biochemical comparisons reveal almost identical antigenic and genomic profiles [25]. Given that $O$. ochengi is readily available and can be obtained at relatively low cost, it is currently regarded as a more practical model in onchocerciasis drug screens [26]. However, no small laboratory animal has been reported as a model to screen drugs on $O$. ochengi mf. This study therefore, was aimed at developing and validating such a model for onchocerciasis based on the use of $O$. ochengi, and verifying the usefulness of the model for $L$. loa $\mathrm{mf}$ counter screens.

\section{Methods}

\section{Animals}

Male and female Syrian hamsters (Mesocricetus auratus) were purchased from Charles River (France) and flown to Cameroon. These animals together with our home-bred
$\mathrm{BALB} / \mathrm{c}$ mice were maintained in a conventional animal house at the Biotechnology Unit of the University of Buea. Animals were given food and water ad libidum. Animals were aged 10-16 weeks at the time of use in the experiments. This in vivo study was reported in accordance with the ARRIVE Guidelines for reporting animal research.

\section{L. loa patients and parasites}

Due to the adverse effects observed during ivermectin treatment of individuals co-infected with Onchocerca and high loads of L. loa $\mathrm{mf}$ [6], we questioned if the hamster and BALB/c mice were also permissive to $L$. loa $\mathrm{mf}$, thereby helping to find safer therapeutic options. $L$. loa endemic areas of Edea and Mfou health districts of the Littoral and Centre regions of Cameroon, respectively, were targeted. Participants included those who consented to participate in the study as L. loa parasite donors after proper understanding of the intended study. Individuals eligible for participation were adults of both sexes, $>21$ years of age, in good health without any clinical condition requiring long term treatment. Exclusion criteria included an $\mathrm{mf}$ load of $<5000 / \mathrm{ml}$ of blood and use of anti-filarial therapy. A maximum of $20 \mathrm{ml}$ of venous blood was collected from eligible individuals at most $24 \mathrm{~h}$ before L. loa mf isolation.

\section{Extraction of $\mathrm{mf}$ \\ O. ochengi mf isolation}

This was done following a method we described previously [15], with slight modifications. Briefly, fresh pieces of nodule-containing umbilical cattle skin were purchased from a local slaughter house, washed repeatedly with tap water until all dirt was removed, and rinsed with distilled water. The skin was towel-dried and sterilized with $70 \%$ ethanol, allowed to dry in a laminar flow hood and firmly attached to an autoclaved cylindrical-shaped wooden block. Using sharp razor blades, criss-cross cuts were made into the skin and submerged in ICM (incomplete culture medium: RPMI-1640 containing penicillin, streptomycin and amphotericin B) for $4 \mathrm{~h}$, after which, the medium was centrifuged at $2500 \mathrm{rpm}$ for 20 mins using an Eppendorf 5810R centrifuge (Eppendorf, Germany) to concentrate the $\mathrm{mf}$. After viability check, the number of $\mathrm{mf}$ were counted and adjusted to the required number for experimental infection $(5000-25,000)$ in $200-1000 \mu \mathrm{l}$ of ICM.

\section{L. loa mf isolation}

$1 \mathrm{~g}$ of medium-grain Sephadex G-50 (Pharmacia Biotech, Uppsala, Sweden) was weighed and allowed to swell overnight in $20 \mathrm{ml}$ of distilled water at $4{ }^{\circ} \mathrm{C}$. Using $25 \mathrm{ml}$ serological pipette as column, the swollen gel (after attaining room temperature) was transferred and allowed to settle to a bed volume of $11 \mathrm{ml}$. This column was equilibrated 
with 2 bed volumes of ICM, which was also the elution buffer.

The number of $L$. loa $\mathrm{mf}$ per $\mathrm{ml}$ of blood was determined microscopically. Then $1 \mathrm{ml}$ of the infected blood was loaded on the column and allowed to just completely enter the gel bed before elution began. The red coloration due to red blood cells was allowed to flow through the gel completely before fraction collection started. A total of $30 \mathrm{ml}$ of eluate was collected for every $\mathrm{ml}$ of blood loaded. Fractions were centrifuged at $2500 \mathrm{rpm}$ for 20 mins using the Eppendorf 5810R centrifuge, supernatants discarded, pellets re-suspended in ICM, pooled and centrifuged as before. Sediments obtained after the second centrifugation were re-suspended in ICM and washed on $20 \%$ percoll at $1000 \mathrm{rpm}$ for 5 mins, thrice using the same centrifuge. After the third wash, the procedure was repeated twice with $1 x$ PBS (phosphate buffered saline) in place of percoll. Sediments were finally re-suspended in a small volume of ICM, and L. loa $\mathrm{mf}$ counted using a microscope.

\section{Experimental infection with 0 . ochengi mf}

Isolated $\mathrm{mf}$ were administered subcutaneously (sc) at 7250-44,100 per animal, in $1 \mathrm{ml}$ of ICM using 29.5G needles at the region behind the ears (nape). Mf were $100 \%$ viable at time of injection.

\section{Experimental infection with $L$. loa $\mathrm{mf}$}

Four hamsters were intraperitoneally infected, each with $30,000 \mathrm{~L}$. loa $\mathrm{mf}$ at a viability of $98.97 \%$ in $2 \mathrm{ml}$ of PBS using syringes with $29.5 \mathrm{G}$ needles. Animals were sacrificed 26 days post-infection and examined for viable $\mathrm{mf}$.

\section{Drug administration}

Ivermectin (Mectizan $^{\text {Ts. }}$; Sigma Aldrich, Germany) was administered to two groups of hamsters (randomly chosen after infection) per os, 3 days post-infection. One group of 5 animals received ivermectin at $150 \mu \mathrm{g} / \mathrm{kg}$ body weight and the other at $600 \mu \mathrm{g} / \mathrm{kg}$ body weight, while control animals received the vehicle (1\% DMSO) only.

\section{Checking animals for presence of $\mathrm{mf}$ \\ O. ochengi $m f$}

For O. ochengi $\mathrm{mf}$ recovery the skin, approximately $0.5 \mathrm{~cm}$ around the ears was completely shaved. Each ear was carefully cut off, rinsed in distilled water, toweldried and sterilized with $70 \%$ ethanol. Each pair of ears was carefully chopped up into tiny bits and incubated in $5 \mathrm{ml}$ of ICM at $37{ }^{\circ} \mathrm{C}$ for $4 \mathrm{~h}$ under sterile conditions. During preliminary tests, the entire animal skin was shaved and the skin of other body parts, including the fore limbs, hind limbs, head, tail and trunk were chopped into tiny pieces and also examined for mf. After incubation, the total number of $\mathrm{mf}$ was obtained by spreading five
$100 \mu \mathrm{l}$ portions of ICM from each well on petri dishes and observing microscopically to count the $\mathrm{mf}$.

\section{L. loa $m f$}

For L. loa mf recovery, $200 \mu \mathrm{l}$ of freshly collected blood obtained by heart puncture of the animal post sedation, were thinly spread on petri dishes in $20 \mu \mathrm{l}$ portions and observed microscopically.

After blood was collected, each animal was sacrificed by cranial dislocation and its peritoneum washed with $50 \mathrm{ml}$ PBS. After microscopic observation, the peritoneal wash obtained was centrifuged at $400 \times \mathrm{g}$ for $15 \mathrm{mins}$, supernatant discarded and pellets resuspended. All $\mathrm{mf}$ in $500 \mu \mathrm{l}$ of the resuspended pellets were counted in $100 \mu \mathrm{l}$ sub-portions, for each animal. The animal organs, including the heart, lungs, liver, spleen, kidneys, intestines, stomach and trunk were removed and chopped into tiny pieces and each set incubated in $7 \mathrm{ml}$ of PBS ( $\mathrm{pH} 7.4$ ), at $37{ }^{\circ} \mathrm{C}$ for $1 \mathrm{~h}$. After incubation as for the ear lobes, portions of the chopped organs in buffer were observed microscopically for the presence of $L$. loa $\mathrm{mf}$.

\section{Data analysis}

Data were analysed using GraphPad Prism 5.0 software and statistical analyses were performed using the KruskalWallis test and Dunn's post-test. Data presented show mean \pm SEM. Data were considered to show statistical significant difference when $p<0.05$.

\section{Results}

The hamster is permissive to $\mathrm{mf}$ of $\mathrm{O}$. ochengi, but not to those of $L$. loa

To test if the Syrian hamster was permissive to $O$. ochengi $\mathrm{mf}$, three preliminary exploratory experiments were done with different numbers of $\mathrm{mf}$ injected in each animal (Table 1). Following exploratory testing of different numbers of $\mathrm{mf}$, the number was finally harmonized to $25,000 \mathrm{mf} /$ animal, unless otherwise stated. In these studies, the hamsters were able to retain $O$. ochengi $\mathrm{mf}$ in the skin detected on day 21 and 30 when the animals were sacrificed. Most of the $O$. ochengi $\mathrm{mf}$ were found in the extremities (ears, head, fore limbs and hind limbs) and less or no $\mathrm{mf}$ in the tail. Interestingly, more than $50 \%$ of the total $O$. ochengi $\mathrm{mf}$ recovered were from the earlobes (Table 1). Preliminary experiments were also done on BALB/C mice to verify their ability to host $O$. ochengi $\mathrm{mf}$ for 30 days. BALB/c mice tolerated $O$. ochengi $\mathrm{mf}$ injected into them for 15 days, but not 30 days, as no $\mathrm{mf}$ was recovered on day 30 . None of the animals analyzed showed any tissue or whole body pathology (Table 1). From these preliminary experiments, the hamster was considered more permissive to $O$. ochengi $\mathrm{mf}$ (day 30 data) and therefore, was used for the rest of the study. In addition, since the earlobes had more than 
Table 1 The Syrian hamster is more permissive to O. ochengi mf than BALB/c mice

\begin{tabular}{|c|c|c|c|c|c|c|c|c|c|c|c|c|c|}
\hline Animal & $\begin{array}{l}\text { Sex } \\
(M / F)\end{array}$ & $\begin{array}{l}\text { Amount of } \\
\text { O. ochengi mf } \\
\text { injected }\end{array}$ & $\begin{array}{l}\text { Percentage viability } \\
\text { of mf at time } \\
\text { of injection }\end{array}$ & $\begin{array}{l}\text { Duration between } \\
\text { mf injection and } \\
\text { sacrifice (days) }\end{array}$ & $\begin{array}{l}N^{\circ} \text { of } \mathrm{mf} \text { in } \\
\text { fore limbs }\end{array}$ & $\begin{array}{l}\mathrm{N}^{0} \text { of } \mathrm{mf} \text { in } \\
\text { hind limbs }\end{array}$ & $\begin{array}{l}\mathrm{N}^{\circ} \text { of } \mathrm{mf} \text { in } \\
\text { ear lobes }\end{array}$ & $\begin{array}{l}\mathrm{N}^{\circ} \text { of } \mathrm{mf} \\
\text { in tail }\end{array}$ & $\begin{array}{l}\mathrm{N}^{\circ} \text { of } \mathrm{mf} \\
\text { in head }\end{array}$ & $\begin{array}{l}\mathrm{N}^{\circ} \text { of } \mathrm{mf} \\
\text { in the trunk }\end{array}$ & $\begin{array}{l}\text { Total } \mathrm{mf} \\
\text { recovered } \\
\text { (\% recovered) }\end{array}$ & $\begin{array}{l}\% \mathrm{mf} \text { recovered } \\
\text { in ear lobes relative } \\
\text { to total recovery }\end{array}$ & $\begin{array}{l}\text { Tissue and } \\
\text { whole body } \\
\text { pathology }\end{array}$ \\
\hline $\begin{array}{l}\text { Hamster } \\
1\end{array}$ & M & 12,558 & $100 \%$ & 21 & 7 & 7 & 60 & 0 & 7 & 0 & $81(0.65)$ & 74.07 & $\begin{array}{l}\text { None } \\
\text { observed }\end{array}$ \\
\hline $\begin{array}{l}\text { Hamster } \\
2\end{array}$ & M & 44,100 & $88 \%$ & 21 & 125 & 100 & 600 & 67 & 117 & 130 & 1039 (2.36) & 57.75 & $\begin{array}{l}\text { None } \\
\text { observed }\end{array}$ \\
\hline $\begin{array}{l}\text { Hamster } \\
3\end{array}$ & M & 25,000 & $100 \%$ & 30 & 27 & 7 & 353 & 0 & 67 & 53 & $507(2)$ & 69.63 & $\begin{array}{l}\text { None } \\
\text { observed }\end{array}$ \\
\hline BALB/C 1 & M & 25,000 & $100 \%$ & 15 & 120 & 20 & 390 & 20 & 610 & 180 & $1340(5.36)$ & 29.10 & $\begin{array}{l}\text { None } \\
\text { observed }\end{array}$ \\
\hline $\mathrm{BALB} / \mathrm{C} 2$ & M & 25,000 & $100 \%$ & 30 & 0 & 0 & 0 & 0 & 0 & 0 & $0(0)$ & 0 & $\begin{array}{l}\text { None } \\
\text { observed }\end{array}$ \\
\hline BALB/C 3 & M & 25,000 & $100 \%$ & 31 & 0 & 0 & 0 & 0 & 0 & 0 & $0(0)$ & 0 & $\begin{array}{l}\text { None } \\
\text { observed }\end{array}$ \\
\hline $\mathrm{BALB} / \mathrm{C} 4$ & M & 25,000 & $100 \%$ & 30 & 0 & 0 & 0 & 0 & 0 & 0 & $0(0)$ & 0 & $\begin{array}{l}\text { None } \\
\text { observed }\end{array}$ \\
\hline BALB/C 5 & $F$ & 25,000 & $100 \%$ & 31 & 0 & 0 & 0 & 0 & 0 & 0 & $0(0)$ & 0 & $\begin{array}{l}\text { None } \\
\text { observed }\end{array}$ \\
\hline
\end{tabular}

Different numbers of $O$. ochengi mf isolated from cattle skin on different days were injected subcutaneously at the nape of different animal types and the animals were sacrificed on indicated days and analyzed for O. ochengi $\mathrm{mf}(n=3-5 /$ group) 
$50 \%$ of the total $O$. ochengi $\mathrm{mf}$ recovered, they were the only sites analyzed for the rest of this study. Unfortunately, after infecting 4 hamsters and $5 \mathrm{BALB} / \mathrm{c}$ mice, no L. loa $\mathrm{mf}$ was recovered from any of the animals (results not shown).

\section{O. ochengi mf recovery reduces with time and is linearly proportional to number administered}

To characterize the $O$. ochengi $\mathrm{mf}$ hamster model, the effect of time on $\mathrm{mf}$ recovery post-infection was assessed. Twenty one days post-infection with 20,000 the $\mathrm{mf}, 1199 \pm 158 \mathrm{mf}$ were recovered from the earlobes, representing $6.0 \%$ of the total $\mathrm{mf}$ injected (Fig. 1). After 30 days, $773 \pm 144$ O. ochengi $\mathrm{mf}$ were recovered from the earlobes, representing $3.9 \%$ of the total $\mathrm{mf}$ injected. The change in mf numbers from $1199 \pm 158$ to $773 \pm$ 144 in the earlobes between day 21 and 30 respectively, marks a $35.5 \%$ drop.

Next, we assessed the effect of number of $O$. ochengi $\mathrm{mf}$ injected on recovery. Hamsters were infected with $5000,10,000$ or $20,000 \mathrm{mf}$ and their earlobes were analyzed on day 30. Interestingly, increasing the number of $\mathrm{mf}$ injected resulted in a linear increase in the number of $\mathrm{mf}$ recovered (Fig. 2). The percentage of $\mathrm{mf}$ recovered from the earlobes on day 30 was $7-8 \%$, irrespective of number of $\mathrm{mf}$ injected.

Ivermectin completely clears 0 . ochengi $\mathrm{mf}$ from hamsters in model validation studies

Finally, to validate the suitability of this model, we used the drug of choice ivermectin. Three days after infection of animals with $O$. ochengi $\mathrm{mf}, 5$ hamsters per group were dosed orally with ivermectin at 150 or $600 \mu \mathrm{g} / \mathrm{kg}$ body weight, or received the vehicle only. When animals were sacrificed on day 30 , all the control animals had $O$.

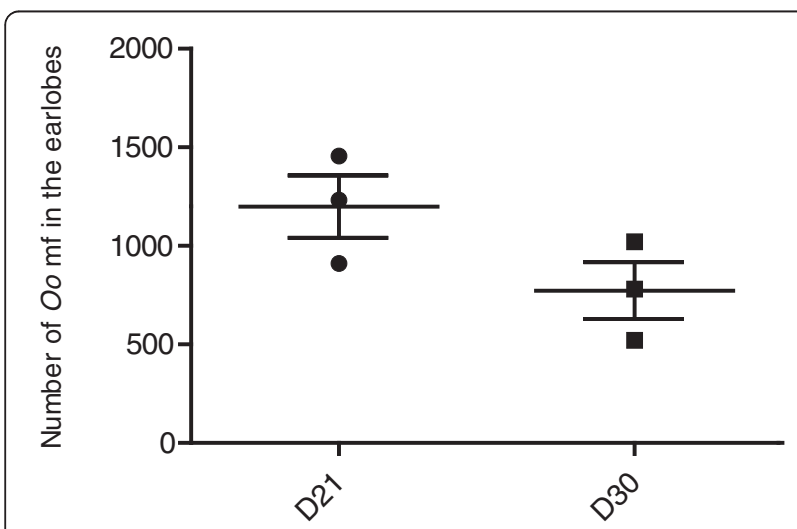

Fig. 1 Population of O. ochengi in hamster decreases overtime. 20,000 0 . ochengi $\mathrm{mf}$ were injected sub-cutaneously (sc) at the nape and animals were sacrificed on day 21 and 30, and $\mathrm{mf}$ recovered from the earlobes and counted ( $n=3 /$ group)

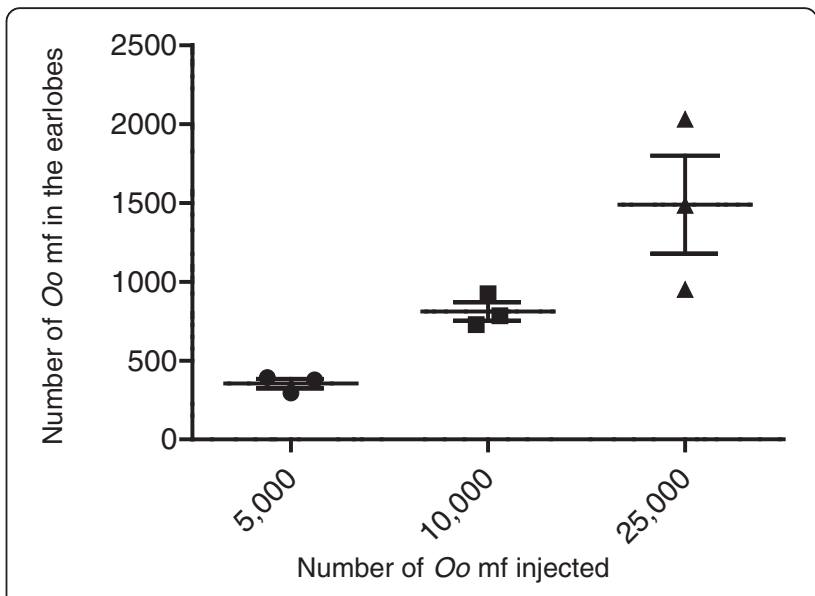

Fig. 2 Recovery of $O$. ochengi $\mathrm{mf}$ in hamster is directly proportional to number of $\mathrm{mf}$ injected. Different numbers of $\mathrm{O}$. ochengi $\mathrm{mf}$ were injected sc at the nape and animals were sacrificed on day 30 and $\mathrm{mf}$ recovered from the earlobes and counted ( $n=3$ /group)

ochengi $\mathrm{mf}$ in the earlobes (Fig. 3). On the contrary, in all the animals treated with ivermectin at 150 or $600 \mu \mathrm{g} / \mathrm{kg}$ body weight, no $O$. ochengi $\mathrm{mf}$ was recovered. The control and treated groups showed a statistical significant difference $(p=0.0013)$ after a Kruskal-Wallis test. Further statistical analysis of each ivermectin-treated group versus the control group with Dunn's post-test indicated they were significantly different (Fig. 3). These results

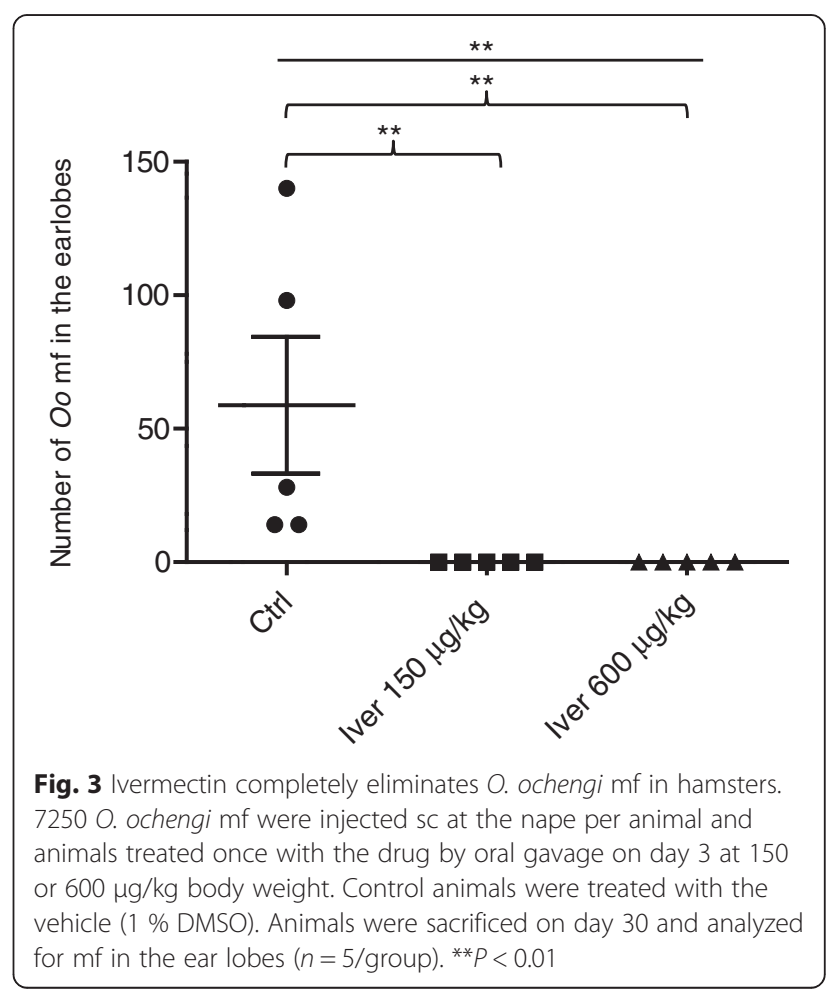


show that the Syrian hamster is a good model to test drugs on $O$. ochengi $\mathrm{mf}$.

\section{Discussion}

The present study was carried out to develop a small immunocompetent animal model for onchocerciasis drug screens, based on the use of bovine-derived O. ochengi, the closest known relative of O. volvulus. Previously developed onchocerciasis $\mathrm{mf}$ models have all been based on use of mice experimentally infected with animal Onchocerca species which are not the closest to O. volvulus. We found for the first time that the Syrian hamster is a suitable model for harboring $O$. ochengi $\mathrm{mf}$ for more than 30 days, without any observable pathology. Although only 3 hamsters were used in preliminary studies (Table 1), the data presented in Figs. 1, 2 and 3 involving different sets of more of the animal all show that the hamster retained $\mathrm{mf}$ until day 30 , fortifying the claim that it is a permissive host. The goal was to maintain $O$. ochengi $\mathrm{mf}$ for 30 days in the model, but we can say that the $\mathrm{mf}$ can survive longer in the hamsters, given that hundreds of $\mathrm{mf}$ were recovered on day 30 . In our opinion, 30 days is enough time to verify reduction in mf viability, not necessarily elimination, with drug testing. None of the animals tested showed any pathology or signs of illness due to the $O$. ochengi $\mathrm{mf}$ infection. The model would enable preclinical drug discovery efforts in vivo to complement already well-established in vitro assays. A simple technique previously developed by our laboratory [15], permits the production of large quantities (hundreds of thousands) of $O$. ochengi $\mathrm{mf}$ for the screens, from an $\mathrm{mf}$ rich cattle skin obtainable from local slaughterhouses.

$\mathrm{BALB} / \mathrm{c}$ mice were able to retain $O$. ochengi $\mathrm{mf}$ for 15 days. However, on day 30, no $\mathrm{mf}$ was recovered from all infected BALB/c mice. In contrast, all infected hamsters had many $\mathrm{mf}$ in almost every part of the skin, with the same or even lower number of $\mathrm{mf}$ injected. These observations show that the hamster is more tolerant to $O$. ochengi $\mathrm{mf}$ than $\mathrm{BALB} / \mathrm{c}$ mice on day 30 , and is therefore, a more suitable model for standard onchocerciasis drug screens. The mechanism of $\mathrm{mf}$ clearance by mice or other rodents is not known. From literature it is clear that the immune response plays a critical role in parasite survival in an immunocompetent host. That is why immunocompromised and transgenic animals lacking crucial cytokines like IL- 4 and IL-5 have been exploited to improve filariae survival in mice. But the situation is not straightforward. For example, BALB/c mice are known to be more Th2-biased [27, 28], producing cytokines such as IL-4 and IL-5 which have been implicated in the clearing of filarial parasites from the mammalian host [29-31]. However, some filaria parasites do well in Balb/c mice than in other strains of mouse. But a fully immunocompetent host for drug screens would be better at mimicking the complex situation in humans. Our observation that the fully immunocompetent hamster is better than BALB/c mice in harboring $O$. ochengi $\mathrm{mf}$ for longer periods, suggest that attention should be paid to other small immunocompetent rodents (other than mice), such as gerbils in developing onchocerciasis animal models. Interestingly, other workers have shown that gerbils are permissive to $O$. ochengi adult male worms [32]. The only $O$. ochengi mouse model reported to date is the SCID mouse [32], emphasizing the need to further explore the mouse world for smaller $O$. ochengi-based models of onchocerciasis. This mouse is also permissive to adult $O$. ochengi male and female worms. However, its lack of an adaptive immune system clearly undermines the possible assisting role of an intact immune system in drug-mediated killing of parasites.

Efforts to develop a $L$. loa and O. ochengi $\mathrm{mf}$ coinfection model for drug screens were hindered by the non-permissiveness of the hamster to $L$. loa mf. More research to identify such a co-infection model would be highly beneficial to the scientific community interested in novel onchocerciasis drugs, and is currently one of the main areas of interest in our laboratory. Counter screening systems for verification of inactivity of new drugs on $L$. loa $\mathrm{mf}$ in vivo may help later on in avoiding or mitigating the adverse effects such as those that are observed in onchocerciasis patients co-infected with $L$. loa after ivermectin treatment [6].

As expected, the number of $O$. ochengi $\mathrm{mf}$ in the hamsters drops with duration of infection. The $\mathrm{mf}$ recovery was also directly proportional to the number administered. On day 30 , the maximum recovery was $8 \%$ which is close to the $10 \%$ described in CBA mice 35 days after infection with $O$. lienalis [11]. The percentage of $\mathrm{mf}$ recovered varied between experiments, and this could probably be attributed to genetic differences between the outbred hamsters. The present model was validated with ivermectin. A dose of $150 \mu \mathrm{g} / \mathrm{kg}$ body weight eliminated all $O$. ochengi $\mathrm{mf}$. Therefore, ivermectin will be a good positive control for testing of drugs in this model. This model can be used for drugs that are active on both micro- and macrofilariae or to acquire more data in the study of microfilaricides. It can also be used as counter screen in situations where newly developed macrofilaricide is not expected to be active against $\mathrm{mf}$, to reduce adverse drug effects resulting from dying $\mathrm{mf}$. However, a major limitation of the model is that it is yet to be tested or developed further to include macrofilaricidal drug screens. Further work is on-going to identify novel microfilaricides using the model and to investigate the incorporation of adult worm screens into it. 


\section{Conclusions}

This study has revealed that the Syrian hamster is a model for $O$. ochengi $\mathrm{mf}$, the closest relative of $O$. volvulus. It also revealed that $\mathrm{BALB} / \mathrm{c}$ mice are not permissive to $O$. ochengi $\mathrm{mf}$ by day 30 , although they were on day 15. This is the first small laboratory animal model described for this species of $\mathrm{mf}$ and may serve as an important preclinical complement to in vitro and other in vivo drug screens for onchocerciasis.

\section{Abbreviations}

DMSO, dimethyl sulfoxide; ICM, incomplete culture medium; IL, interleukin; Mf, microfilariae; O.o, Onchocerca ochengi; PBS, phosphate buffered saline; SCID, severe-combined immunodeficient; SEM, standard error of mean

\section{Acknowledgements}

We would like to thank Emmanuel Menang Ndi and Gamua Stanley of the Biotechnology Unit, Faculty of Science, University of Buea, Cameroon, for their technical support.

\section{Funding}

This project received support from WHO/TDR under grant $N^{\circ}$ A70107. The funding body had no role in the design of the study, the collection of data, the analysis and interpretation of data, or the manuscript preparation.

\section{Availability of data and materials}

The datasets supporting the conclusions of this article are included within the article.

\section{Authors' contributions}

GE performed the experiments, analyzed the results, and drafted the manuscript; RB co-performed the experiments, analyzed the results, and drafted the manuscript; FCN did the conception, sourced for funding, designed and supervised the experiments, and corrected the manuscript. All authors read and approved the final manuscript.

\section{Authors' information}

GE and RB are members of the Biotechnology Unit, Faculty of Science, University of Buea. FC is the Head of the ANDI (WHO/TDR/UNOPS) Centre of Excellence for Onchocerciasis Drug Research and Coordinator of the Biotechnology Unit, Department of Biochemistry and Molecular Biology, Faculty of Science, University of Buea. All authors read and approved the final version of the manuscript.

\section{Competing interests}

The authors declare that they have no competing interest.

\section{Consent for publication}

Not applicable.

\section{Ethics approval and consent to participate}

Ethical approval N²013/11/371/L/CNERSH/SP for the use of human blood samples in this study was obtained from the Cameroon National Ethics Committee for Research on Human Health, while administrative clearance $N^{\circ}$ 631-06.14 was obtained from the Cameroon Ministry of Public Health in Yaounde. Participants included those who consented to participate in the study as $L$. loa parasite donors after proper understanding of the intended study. The animal protocol IACUC N ${ }^{\circ}$ UBAP2014-001 was approved by the provisional Animal Care and Use Committee of the Faculty of Science, University of Buea.

Received: 12 February 2016 Accepted: 4 August 2016

Published online: 11 August 2016

\section{References}

1. Fenwick A. The global burden of neglected tropical diseases. Public Health. 2012;126(3):233-6. doi:10.1016/j.puhe.2011.11.015.

2. Coffeng LE, Stolk WA, Zouré HGM, Veerman JL, Agblewonu KB, Murdoch ME, et al. African programme for onchocerciasis control 1995-2015: updated health impact estimates based on new disability weights. PLoS Negl Trop Dis. 2014;8(6):e2759. doi:10.1371/journal.pntd.0002759.

3. Babalola OE. Ocular onchocerciasis: current management and future prospects. Clin Ophthalmol. 2011;5:1479-91. doi:10.2147/opth.s8372.

4. Burnham G. Onchocerciasis. Lancet. 1998;351(9112):1341-6. doi:10.1016/ s0140-6736(97)12450-3.

5. Pearlman E, Lass JH, Bardenstein DS, Kopf M, Hazlett Jr FE, Diaconu E, et al. Interleukin 4 and $T$ helper type 2 cells are required for development of experimental onchocercal keratitis (river blindness). J Exp Med. 1995;182(4): 931-40.

6. Gardon J, Gardon-Wendel N, Demanga N, Kamgno J, Chippaux JP, Boussinesq M. Serious reactions after mass treatment of onchocerciasis with ivermectin in an area endemic for Loa loa infection. Lancet. 1997;350(9070): 18-22. doi:10.1016/s0140-6736(96)11094-1.

7. Taylor MJ, Awadzi K, Basanez MG, Biritwum N, Boakye D, Boatin B, et al. Onchocerciasis control: vision for the Future from a Ghanian perspective. Parasit Vectors. 2009:2(1):7. doi:10.1186/1756-3305-2-7.

8. Osei-Atweneboana MY, Awadzi K, Attah SK, Boakye DA, Gyapong JO, Prichard RK. Phenotypic evidence of emerging ivermectin resistance in Onchocerca volvulus. PLoS Negl Trop Dis. 2011;5(3):e998.

9. Bianco AE. Onchocerciasis-river blindness. In: MacPherson CNL, Craig PS editors. Parasitic helminths, zoonoses and human health in Africa. London: Unwin Hyman Press; 1991. p. 138-203.

10. Townson S, Dobinson A, Connelly C, Muller R. Chemotherapy of Onchocerca lienalis microfilariae in mice: a model for the evaluation of novel compounds for the treatment of onchocerciasis. J Helminthol. 1988;62(03): 181-94. doi:10.1017/S0022149X00011494.

11. Townson S, Bianco AE. Experimental infection of mice with the microfilariae of Onchocerca lienalis. Parasitology. 1982;85(Pt 2):283-93.

12. Folkard SG, Taylor MJ, Butcher GA, Bianco AE. Protective responses against skin-dwelling microfilariae of Onchocerca lienalis in severe combined immunodeficient mice. Infect Immun. 1997;65(7):2846-51.

13. Bianco AE, Nwachukwu MA, Townson S, Doenhoff MJ, Muller RL. Evaluation of drugs against Onchocerca microfiliariae in an inbred mouse model. Trop Med Parasitol. 1986;37(1):39-45

14. Morales-Hojas R, Cheke RA, Post RJ. Molecular systematics of five Onchocerca species (Nematoda: Filarioidea) including the human parasite, $\mathrm{O}$. volvulus, suggest sympatric speciation. J Helminthol. 2006;80(3):281-90.

15. Cho-Ngwa F, Abongwa M, Ngemenya MN, Nyongbela KD. Selective activity of extracts of Margaritaria discoidea and Homalium africanum on Onchocerca ochengi. BMC Complement Altern Med. 2010;10:62. doi:10.1186/1472-6882-10-62.

16. Bulman CA, Bidlow CM, Lustigman S, Cho-Ngwa F, Williams D, Rascón JAA, et al. Repurposing auranofin as a lead candidate for treatment of lymphatic filariasis and onchocerciasis. PLoS Negl Trop Dis. 2015;9(2):e0003534. doi:10. 1371/journal.pntd.0003534.

17. Samje M, Metuge J, Mbah J, Nguesson B, Cho-Ngwa F. In vitro antiOnchocerca ochengi activities of extracts and chromatographic fractions of Craterispermum laurinum and Morinda lucida. BMC Complement Altern Med. 2014:14:325. doi:10.1186/1472-6882-14-325.

18. Metuge JA, Babiaka SB, Mbah JA, Ntie-Kang F, Ayimele GA, Cho-Ngwa F. Anti-onchocerca metabolites from Cyperus articulatus: Isolation, in vitro activity and in silico 'drug-likeness'. Nat Prod Bioprospect. 2014;4(4):243-9. doi:10.1007/s13659-014-0023-5.

19. Dec Bronsvoort BM, Makepeace BL, Renz A, Tanya VN, Fleckenstein L, Ekale D, et al. UMF-078: a modified flubendazole with potent macrofilaricidal activity against Onchocerca ochengi in African cattle. Parasit Vectors. 2008;1(1):18. doi: 10.1186/1756-3305-1-18.

20. Gilbert J, Nfon CK, Makepeace BL, Njongmeta LM, Hastings IM, Pfarr KM, et al. antibiotic chemotherapy of onchocerciasis: in a bovine model, killing of adult parasites requires a sustained depletion of endosymbiotic bacteria (Wolbachia species). J Infect Dis. 2005;192(8):1483-93. doi:10.1086/462426.

21. Trees AJ, Graham SP, Renz A, Bianco AE, Tanya V. Onchocerca ochengi infections in cattle as a model for human onchocerciasis: recent developments. Parasitology. 2000;120(Suppl):S133-42.

22. Wildenburg G, Plenge-Bonig A, Renz A, Fischer P, Buttner DW. Distribution of mast cells and their correlation with inflammatory cells around Onchocerca gutturosa, O. tarsicola, O. ochengi, and O. flexuosa. Parasitol Res. 1997:83(2):109-20

23. McCall PJ, Townson H, Trees AJ. Morphometric differentiation of Onchocerca volvulus and O. ochengi infective larvae. Trans R Soc Trop Med Hyg. 1992; 86(1):63-5. 
24. Langworthy NG, Renz A, Mackenstedt U, Henkle-Duhrsen K, de Bronsvoort MB, Tanya VN, et al. Macrofilaricidal activity of tetracycline against the filarial nematode Onchocerca ochengi: elimination of Wolbachia precedes worm death and suggests a dependent relationship. Proc Biol Sci. 2000;267(1448): 1063-9. doi:10.1098/rspb.2000.1110.

25. Xie H, Bain O, Williams SA. Molecular phylogenetic studies on filarial parasites based on 5 S ribosomal spacer sequences. Parasite. 1994;1(2):141-51.

26. Trees AJ. Onchocerca ochengi: mimic, model or modulator of 0 . volvulus? Parasitol Today. 1992;8(10):337-9. doi:10.1016/0169-4758(92)90068-D.

27. Okamoto $M$, Van Stry $M$, Chung $L$, Koyanagi $M$, Sun $X$, Suzuki $Y$, et al. Mina, an II4 repressor, controls T helper type 2 bias. Nat Immunol. 2009;10(8):872-9. doi:10.1038/ni.1747.

28. Paul WE, Zhu J. How are $T(H) 2$-type immune responses initiated and amplified? Nat Rev Immunol. 2010;10(4):225-35. doi:10.1038/nri2735.

29. Tendongfor N, Wanji S, Ngwa JC, Esum ME, Specht S, Enyong P, et al. The human parasite Loa loa in cytokine and cytokine receptor gene knock out BALB/c mice: survival, development and localization. Parasit Vectors. 2012;5:43. doi:10.1186/1756-3305-5-43

30. Allen JE, Adjei O, Bain O, Hoerauf A, Hoffmann WH, Makepeace BL, et al. Of mice, cattle, and humans: the immunology and treatment of river blindness. PLoS Negl Trop Dis. 2008;2(4):e217.

31. Volkmann L, Bain O, Saeftel M, Specht S, Fischer K, Brombacher F, et al. Murine filariasis: interleukin 4 and interleukin 5 lead to containment of different worm developmental stages. Med Microbiol Immunol. 2003;192(1): 23-31. doi:10.1007/s00430-002-0155-9.

32. Halliday A, Guimaraes A, Tyrer $\mathrm{H}$, Metuge $\mathrm{H}$, Patrick $\mathrm{C}$, Arnaud K-O et al. A murine macrofilaricide pre-clinical screening model for onchocerciasis and lymphatic filariasis. Parasit Vectors. 2014;7(1):1-14. doi:10.1186/s13071-0140472-z.

\section{Submit your next manuscript to BioMed Central and we will help you at every step:}

- We accept pre-submission inquiries

- Our selector tool helps you to find the most relevant journal

- We provide round the clock customer support

- Convenient online submission

- Thorough peer review

- Inclusion in PubMed and all major indexing services

- Maximum visibility for your research

Submit your manuscript at www.biomedcentral.com/submit 